\title{
Differential expression of centrosome regulators in Her2+ breast cancer cells versus non-tumorigenic MCF10A cells
}

\author{
Mi-Young Lee ${ }^{1 \dagger}$, Mihaela Marina ${ }^{1 \dagger}$, Jamie L King ${ }^{1,2}$ and Harold I Saavedra ${ }^{1 *}$
}

\begin{abstract}
Centrosome amplification (CA) amongst particular breast cancer subtypes (Her2+ subtype) is associated with genomic instability and aggressive tumor phenotypes. However, changes in signaling pathways associated with centrosome biology have not been fully explored in subtype specific models. Novel centrosome regulatory genes that are selectively altered in Her2+ breast cancer cells are of interest in discerning why CA is more prevalent in this subtype. To determine centrosome/cell cycle genes that are altered in Her2+ cells that display CA (HCC1954) versus non-tumorigenic cells (MCF10A), we carried out a gene microarray. Expression differences were validated by real-time PCR and Western blotting. After the microarray validation, we pursued a panel of upregulated and downregulated genes based on novelty/relevance to centrosome duplication. Functional experiments measuring $C A$ and $B r d U$ incorporation were completed after genetic manipulation of targets (TTK, SGOL1, MDM2 and SFRP1). Amongst genes that were downregulated in HCC1954 cells, knockdown of MDM2 and SFRP1 in MCF10A cells did not consistently induce CA or impaired BrdU incorporation. Conversely, amongst upregulated genes in HCC1954 cells, knockdown of SGOL1 and TTK decreased CA in breast cancer cells, while BrdU incorporation was only altered by SGOL1 knockdown. We also explored the Kaplan Meier Plot resource and noted that MDM2 and SFRP1 are positively associated with relapse free survival in all breast cancer subtypes, while TTK is negatively correlated with overall survival of Luminal A patients. Based on this functional screen, we conclude that SGOL1 and TTK are important modulators of centrosome function in a breast cancer specific model.
\end{abstract}

Keywords: Centrosome amplification, Cell cycle, Her2+ breast cancer, SFRP1, MDM2, SGOL1, TTK

\section{Introduction}

Breast cancer is the most common form of cancer detected globally and the second leading cause of cancer-related deaths in women. Fatality from breast cancer is mostly due to metastasis and the risk of metastasis and relapse partially correlates with tumor heterogeneity. Chromosome instability (CIN) -defined as the active gain or loss of whole or fragments of chromosomes during cell division- and aneuploidy -the state of having abnormal chromosome numbers- remain uncontested sources of genetic heterogeneity and are associated with the most aggressive breast tumor types [1]. Equal segregation of chromosomes into

\footnotetext{
* Correspondence: hsaaved@emory.edu

${ }^{\dagger}$ Equal contributors

'Department of Radiation Oncology, Winship Cancer Institute, Emory University School of Medicine, C3084, 1365C Clifton Road NE, Atlanta, GA 30322, USA

Full list of author information is available at the end of the article
}

daughter cells and the maintenance of euploidy are ensured by the two mitotic centrosomes that direct the formation of a bipolar spindle [2].

Various molecular alterations, such as expression of oncogenes and deregulation of proteins that control the centrosome cycle, the spindle assembly checkpoint or the cell cycle culminate in centrosome amplification (CA), defined as the presence of more than a pair of centrosomes within a cell $[2,3]$. For example, we reported that a subset of Her2+ cell lines display CA, which strongly correlated with increased protein expression of the centrosome kinases Nek2 and Plk4 [4]. Both of these proteins, when overexpressed, induced CA in mammary epithelial cells previously devoid of CA [5-7]. Emerging evidence suggests that $\mathrm{CIN}$ and aneuploidy, including single chromosome losses and polyploidy, can ensue from CA and/or cytokinesis defects $[2,8-10]$. CA has been detected in pre-malignant lesions, DCIS (ductal carcinoma in situ) and in invasive 
breast tumors [11-14]. In addition, CA significantly correlates with amplification of the Her2 receptor, which affects over $20 \%$ breast cancer patients, specifically patients displaying the Her2 + ER-PR- and luminal B subtypes [11,12]. Moreover, genomically unstable and more aggressive aneuploid breast cancers have a greater extent of CA and abnormal mitotic spindles compared to genomically stable aneuploid and diploid tumors. In conclusion, preventing the acquisition of $\mathrm{CA}$, by targeting the proteins that enable it, could potentially prevent cancer initiation and tumor progression.

Our screening of breast cancer cell lines revealed that CA is prevalent in a subset of Her2+ cells. Therefore, we chose to use these cell lines as our model of breast cancer displaying CA. We found that E2F activators, Cdk4 and Nek2 kinases are overexpressed and/or deregulated in these cell lines compared to non-tumorigenic mammary epithelial cells $[15,16]$. Using genetic manipulation approaches, we identified that these proteins are required for the maintenance of CA and binucleation in Her2+ breast cancer cells. However, since these molecules regulate a plethora of biological processes, including cell cycle progression, mitosis and cell proliferation, their potential value as selective modifiers of CA is limited.

Here, we present data from gene array experiments performed in order to identify novel centrosome and cell cycle genes that might be selectively modified in Her2+ breast cancer cells versus non-tumorigenic cells. Our aim was to identify differences in gene expression between breast cancer cells with high percentages of CA and nontransformed cells. We hypothesized that genes that are selectively expressed translate into deregulated centrosome functions and might provide therapeutic targets to specifically address CA.

We identified several molecules that might establish a CA phenotype in Her2+ breast cancer cells. Specifically, breast cancer cells overexpressed GINS2, TTK, CEP192, and shugoshin 1 and have lower levels of C-Nap1, semaphorin 6A, MDM2 and SFRP1. Some of these proteins have been previously linked to CA and breast cancer progression, while others have relatively unknown functions in this context. Our findings provide relevant insight into genetic and functional differences in centrosome regulators between breast cancer and non-tumorigenic cells. Potentially, selectively expressed proteins may represent biomarkers for the identification of Her2+ tumors prone to develop CA and other forms of genomic instability, as well as novel therapeutic targets against CA to prevent tumor initiation and disease progression.

\section{Materials and methods Cell culture}

All cell lines were obtained from the ATCC or from collaborators. Culture conditions for MCF10A,
HCC1954, SKBR3 and JIMT-1 cells have been described $[17,18]$.

\section{Data acquisition and processing}

Total RNA was isolated using RNeasy mini kit (Qiagen) and subjected to quality control assessment. Affymetrix Gene Expression microarrays (Affymetrix) were used according to the manufacturer's protocol. Raw intensities of the arrays (2 for MCF10A/pLKO.1 and 2 for HCC1954/ pLKO.1 cells) were normalized using quantile normalization and then $\log 2$ transformed in the Affymetrix Human U133 platform prior to doing the analyses. Distribution of the samples was calculated and $20 \%$ top differentially expressed genes were selected for comparative analysis. Averaged data were then uploaded into Metacore where gene expression probe names were identified and differentially expressed genes (fold threshold $\geq 1.5$ ) for centrosome and cell cycle $\mathrm{GO}$ processes were displayed and further analyzed.

\section{RNA extraction and real-time PCR analysis}

Two $\mu$ g of RNA were used to synthesize cDNA (Promega) following the manufacturer's protocols. Next, two $\mu \mathrm{L}$ of 1:10 diluted cDNA were used for real-time PCR with iQ SYBR Green supermix (170-8880, Bio-Rad). Actin was loaded as an internal control. Primer sequences (Integrated DNA Technologies) are presented in Table 1.

\section{siRNA transfection}

Cells were seeded overnight in either $60 \mathrm{~mm}$ culture dishes or in four well chamber slides (Thermo Scientific). Lipofectamine RNAiMAX (13778075, Life Technologies), along with two hundred pmoles of each of the MDM2, SFRP1, SGOL1 and TTK siRNA constructs (Integrated DNA Technologies) or $5 \mu \mathrm{L}$ of silencer negative control siRNA \#1 $(50 \mu \mathrm{M})$ (AM4611, Life Technologies) were transfected for 48 hours. siRNA sequences are presented in Table 1.

\section{Immunofluorescence for Bromodeoxyuridine (BrdU) incorporation and centrosome amplification}

BrdU staining was performed as described in our publication [8]. Briefly, forty-eight hours post transfection, BrdU was incubated in the media of cells grown in four well chamber slides at a final concentration of $10 \mu \mathrm{M}$ for 30 min prior to fixing the cells in $4 \%$ paraformaldehyde for $10 \mathrm{~min}$. DNA was denatured in $2 \mathrm{~N} \mathrm{HCl}$ for $20 \mathrm{~min}$ at room temperature, followed by neutralization in $0.1 \mathrm{M}$ sodium borate $\mathrm{pH} 8.5$ for 2 minutes. Next, cells were permeabilized in $0.1 \%$ NP-40 solution for $10 \mathrm{~min}$ after three consecutive washes with PBS and then blocked in 10\% normal goat serum (Life Technologies) for $1 \mathrm{~h}$ before incubation with anti-BrdU antibody (NA61, Calbiochem) at $4^{\circ} \mathrm{C}$ overnight. DAPI $(1 \mathrm{mg} / \mathrm{mL})$ counterstain was used. 
Primers used for real-time PCR

\section{Genes}

AURAK_F

AURAK_R

CDC14B_F

CDC14B_F

CDK1_F

CDK1_R

CEP192_F

CEP192_R

CETN2_F

CETN2_R

GINS2_F

GINS2_R

ROCK2_F

ROCK2_R

SASS6-F

SASS6_R

SPICE_F

SPICE_R

SGOL1_F

SGOL1_R

CDK14 F

CDK14_R

C-Nap_F

c-Nap_R

MDM2_F

MDM2_R

PlexinA2_F

PlexinA2_R

SEMA6A_F

SEMA6A_R

SFRP1_F

SFRP1_R

Actin_F

Actin_R

TTK_F

TTK_R

\section{siRNA duplexes}

MDM2_1 Sense

MDM2_1 Anti-Sense

MDM2_2 Sense

MDM2_2 Anti-Sense

SFRP1_2 Sense

SFRP1_2 Anti-Sense

\section{Primer sequences}

5'-ATA TCT CAg Tgg Cgg ACg Ag-3'

5'-TCA AAT ATC CCC gCA CTC Tgg-3'

5'-CTC CAT gAA gCg gAA AAg Cg-3'

5'-gCA AAA CAA Agg CgA TCg gT-3'

5'-AAA CTg gCT gAT TाT ggC CT-3'

5'-ggA gTg CCC AAA gCT CTg AA-3'

5'-CCC gAg CAC TTg ATT CTg gT-3'

5'-CCA CTC CAC ggg AAC ATT gA-3'

5'-AgC ggA CTC CTT Tgg CTA Tg-3'

5'-gCT CAg gCT TAg ggC TCA TT-3'

5'-gCC gAg AAg gAg CTg gTT AC-3'

5'-AAC CAg ggT TAA AAg gCC CC-3'

5'-CCC ATC AAC gTg gAg AgC TT-3'

5'-TgC CTा gTg ACg AAC CAA CT-3'

5'-TAC ggA ATg AAT ggg CgT CA-3'

5'-CTg TgC CTg CAA ggC $\Pi \pi$ Tा-3'

5'-ggT CCC CgA gTT ggT gTA Ag-3'

5'-gCg TAC CAg ATC TTC ggg Ag-3'

5'-Agg CAA AAg ATg gCC AAg gA-3'

5'-AAA gAC CTg CgT TTg CCA AT-3'

5'-AAT gAg gAC ACA Tgg CCT gg-3'

5'-CTg TgC CgA CAg TCT gTT CT-3'

5'-AAC CAg CTC Cgg gAg AAA Tg-3'

5'-TCT ggC ATA ggg CAC TCT CT-3'

5'-CCA TgC CTg CCC ACT TTA gA-3'

5'-CAg gCT gCC ATg TgA CCT AA-3'

5'-ATT TाT CAg CCg AgA ggg Cg-3'

5'-TाT TTC CAg CgC gAC TाT CC-3'

5'-TgA TgC CAA ACA TgC CAA Cg-3'

5'-gCg TCA ATg gCA Agg AAg TC-3'

5'-CTC AAC AAg AAC TgC CAC gC-3'

5'-CTC gTT gTC ACA ggg Agg AC-3'

5'-CgA ggC CCA gAg CAA gAg-3'

5'-CgT CCC AgT Tgg TAA CAA TgC-3'

5'-CgC AgC TाT CTg TAg AAA TggA-3'

5'-gAg CAT CACTTAGCGGAACAC-3'

5'-rGrGrA rCrCrU rUrGrU rArCrA rArGrA rGrCrU rUrCrA rGrGA A-3'

5'-rUrUrC rCrUrG rArArG rCrUrC rUrUrG rUrArC rArArG rGrUrC rCrUrU-3'

5'-rCrCrA rArGrA rCrArA rArGrA rArGrA rGrArG rUrGrU rGrGA A-3'

5'-rUrUrC rCrArC rArCrU rCrUrC rUrUrC rUrUrU rGrUrC rUrUrG rGrGrU-3'

5'-rGrArA rGrCrA rArCrA rGrCrU rUrCrA rGrArA rArGrA rGrCT C-3'

5'-rGrArG rCrUrC rUrUrU rCrUrG rArArG rCrUrG rUrUrG rCrUrU rCrCrU-3' 
Table 1 Primers sequences used for real-time PCR and siRNA duplexes (Continued)

\begin{tabular}{|c|c|}
\hline SFRP1_3 Sense & 5'-rGrArA rArCrA rUrUrU rCrCrU rUrUrG rArArC rUrUrG rArUT G-3' \\
\hline SFRP1_3 Anti-Sense & 5'-rCrArA rUrCrA rArGrU rUrCrA rArArG rGrArA rArUrG rUrUrU rCrUrU-3' \\
\hline TTK_1 Sense & 5'-rGrGrArGrGrUrUrCrArArGrCrArArGrGrUrArUrUrUrCrAGG-3' \\
\hline TTK_1 Anti-Sense & 5'rCrCrUrGrArArArUrArCrCrUrUrGrCrUrUrGrArArCrCrUrCrCrArC-3' \\
\hline TTK_2 Sense & 5'-rCrCrArGrArArUrCrCrUrGrCrUrGrCrArUrCrUrUrCrArAAT-3' \\
\hline TTK_2 Anti-Sense & 5'-rArUrUrUrGrArArGrArUrGrCrArGrCrArGrGrArUrUrCrUrGrGrUrU-3' \\
\hline SGOL1_1 Sense & 5'-rGrArArArUrArUrGrUrUrCrCrUrCrUrGrGrArArUrGrGrACC-3' \\
\hline SGOL1_1 Anti-Sense & 5'-rGrGrUrCrCrArUrUrCrCrArGrArGrGrArArCrArUrArUrUrUrCrCrU-3' \\
\hline SGOL1_2 Sense & 5'-rGrGrArCrUrArCrArGrGrCrArUrGrUrGrCrCrArCrUrArCGC-3' \\
\hline SGOL1_2 Anti-Sense & 5'-rGrCrGrUrArGrUrGrGrCrArCrArUrGrCrCrUrGrUrArGrUrCrCrCrA-3' \\
\hline
\end{tabular}

Five hundred cells were counted and the percentages of BrdU + cells were calculated using fluorescent microscopy.

Centrosome amplification in transiently transfected cells was addressed using four well slides. Forty-eight hours post transfection, cells were fixed in $4 \%$ paraformaldehyde for $10 \mathrm{~min}$, washed in PBS, permeabilized in $0.1 \%$ NP-40 solution for $10 \mathrm{~min}$ and blocked in 10\% normal goat serum (Life Technologies) for $1 \mathrm{~h}$, followed by overnight incubation with primary antibody against pericentrin (ab4448, Abcam). Alexa Fluor-conjugated antibodies (A11008, A11001 or A21069, Life Technologies) were used as secondary antibodies by incubating $1 \mathrm{~h}$ at room temperature. As a counter staining, DAPI $(1 \mathrm{mg} / \mathrm{mL})$ was applied. Two hundred cells were counted and cells with $\geq 3$ pericentrin positive cells were presented as percentages.

\section{Western blotting}

Western blotting was performed according to our published protocols $[8,15,19]$. The following primary antibodies were used: MDM2 (sc-965, Santa Cruz Biotechnology), SEMA6A (ab72369, Abcam), SFRP1 (ab126613, Abcam), shugoshin 1 (ab21633, Abcam) and TTK (3255S, Cell Signaling). Beta-actin antibody (4970, Cell Signaling) was used as a loading control. For secondary antibodies, either goat anti-rabbit HRP (sc-2004, Santa Cruz Biotechnology) or goat anti-mouse HRP (sc-2005, Santa Cruz Biotechnology) were used. Signals were detected by using a Lumigen TMA-6 reagent (Lumigen Inc).

\section{Statistical analysis}

Student $t$-test was applied to compare the significances between control and siRNA transfected counterparts. P value $\leq 0.05$ is considered as significant.

\section{Results}

\section{Analysis of microarray targets}

HCC1954 is a Her2+ breast cancer cell line that displays approximately $10 \% \mathrm{CA}$ in unsynchronized populations, significantly higher compared to MCF10A non-transformed cells $[4,15,16]$. In a parallel microarray assay (Lee and
Saavedra, unpublished), we aimed to identify genes differentially expressed between HCC1954 cells silenced for E2F3 and cells expressing empty vector control (HCC1954/ pLKO.1). For that purpose, we used the lentiviral pLKO.1puro shRNA system to silence E2F3. The microarray analysis presented here compared the gene expression between HCC1954 cells and MCF10A cells and was carried out in HCC1954 cells expressing the empty lentiviral pLKO.1puro vector. For consistency, MCF10A/pLKO.1 nontumorigenic cells were used as comparison. We first selected the top $20 \%$ genes that were differentially distributed across the microarray samples and performed Metacore gene enrichment analysis. The selected targets fell into various categories, with genes involved in $\mathrm{S}$ phase regulation and DNA damage checkpoint control being the most highly represented (Table 2). Our initial screening generated 2135 genes under expressed in HCC1954 versus MCF10A cells. On the other hand, the microarray data identified 2635 genes upregulated in HCC1954 cells relative to MCF10A. Following the analysis for centrosome and cell cycle GO processes, we narrowed down our findings to genes with $\geq 1.5$ fold higher expression in MCF10A vs HCC1954 cells and found 169 for cell cycle and 7 for centrosome with an overlap of 3 genes between the two GOs. The downstream GO analysis indicated that 421 genes with $\geq 1.5$ higher expression in HCC1954 cells were involved in the cell cycle, 23 were linked to the centrosome and 21 genes pertained to both GOs (Table 3).

\section{Validation of microarray targets}

Based on fold changes and our interests, we selected genes that were upregulated (AURKA, CDC14B, CDK1, CEP192, CETN2, GINS2, ROCK2, SASS6, SPICE, TTK and SGOL1) as well as downregulated (CDK14, C-Nap1, MDM2, PlexinA2, SEMA6A, and SFRP1) in HCC1954 cells compared to non-tumorigenic MCF10A cell line. In addition, JIMT-1 cells, a second Her2+ cell line with high CA $[4,16]$, were included in this analysis to investigate the similarity of molecular patterns between two 
Table 2 Enrichment analysis report by process networks

\begin{tabular}{|c|c|c|c|}
\hline Number & Networks & $\begin{array}{l}\text { HCC1954 vs MCF10A } \\
\text { (P value) }\end{array}$ & Genes \\
\hline 1 & Cell cycle, S phase & $6.7436787067153 \mathrm{E}-13$ & $\begin{array}{l}\text { RFC4, TOP2 beta, Chk2, MCM3, SG2NA, NFBD1, Brca1, Cyclin B, Cyclin B2, CRM1, } \\
\text { CHMP1A, ORC1L, MCM5, Nek2A, MCM4, PRIM2A, MCM10, ORC3L, DERPC, Histone } \\
\text { H1.5, ChAF1 subunit B, ORC6L, ASK (Dbf4), POLA1, POLE2, FEN1, DNA ligase I, p21, } \\
\text { RFC5, BUB1, Geminin, Sgo1, Rad51, DNA polymerase alpha/primase, PRIM1, HP1, } \\
\text { Securin, CDK1 (p34), C-Nap1 (CEP2), Ubiquitin, PCNA, CDC18L (CDC6), Cyclin A1, } \\
\text { UHRF2, BRIP1, RFC3, POLD reg (p68), ATM, TOP2 alpha, POLE3-POLE4 complex, MCM6, } \\
\text { POLA2, GADD45 alpha, RFC1, RFC2, Cyclin A, DNA polymerase sigma, PCTK1, TOP2, } \\
\text { ZAK, Cdt1, Cyclin B1, POLE3 (YBL1), p53, RFC complex, Emi1, Nibrin, PKA-cat } \\
\text { (cAMP-dependent), Rad21, RPA2, Histone H4, DCC1, Histone H1, CDC45L }\end{array}$ \\
\hline
\end{tabular}

RFC4, CIA/ASF1, p38alpha (MAPK14), Chk2, 14-3-3 epsilon, NFBD1, Brca1, Cyclin B, Cyclin B2, Cyclin D3, HUS1, CDC25C, ANAPC11, ERK1/2, Cyclin D, 14-3-3, Rad50, CDC25A, BTG2, p21, RFC5, Securin, CDK1 (p34), ANAPC7, Cyclin D2, Ubiquitin, PCNA, CDC23, Cyclin A1, MRE11, BRIP1, RFC3, MRN complex, FANCD2, RAD1, ATM, MDM2, GADD45 alpha, RFC1, Ku70, RFC2, Cyclin A, Cyclin D1, JNK(MAPK8-10), NF-kB, 14-3-3 eta, p38gamma (MAPK12), RUVBL2, p53, RFC complex, Bard1, USP1, Nibrin, p38 MAPK, Rad21

Tubulin beta, Tubulin gamma, MIS12, HZwint-1, Cyclin B, Cyclin B2, ZW10, CAPZ beta, Nek2A, CDC25C, Tubulin alpha 1A, CENP-A, ANAPC11, MACF1, MAD2a, CENP-H, SPBC25, Importin (karyopherin)-alpha, Rod, RCC1, CAP-D2/D3, Kid, CDC25A, USP16, BUB1, MPP6, Dynamin-2, Aurora-A, Actin, CDC25, CDCA1, HP1, Securin, CDK1 (p34), SIL, ANAPC7, Ubiquitin, CDC23, PARP-2, Tubulin alpha, Dynein 1, cytoplasmic, heavy chain, Tctex-1, Survivin, Karyopherin alpha 2, MAPRE3(EB3), Dynamin-3, ANAPC10, DLC1 (Dynein LC8a), BUBR1, CAP-H/H2, NF45 (ILF2), Cyclin A, EML4, HEC, TTK, CAS-L, TOP2, MAD2L1BP, 14-3-3 eta, Dynamin, MCAK, Cyclin B1, PAFAH alpha (LIS1), RAE1, PARD6, HP1 gamma, Rad21, Zwilch, NSL1, Histone H1, Tubulin (in microtubules)

TOP2 beta, p38alpha (MAPK14), Chk2, TCP1-theta, 14-3-3 epsilon, EGF, TCP1-delta, NFBD1, Brca1, Cyclin B, Cyclin B2, GRB2, HUS1, Nek2A, CDC25C, HIPK2, p38delta (MAPK13), EGFR, ANAPC11, NEDD8, MAD2a, ERK1/2, 14-3-3, Histone H1.5, Centrin-2, RCC1, Rad50, CAP-D2/D3, Kid, CDC25A, p21, BUB1, Rad51, CDK10, Aurora-A, CDC25, p90Rsk, Securin, CDK1 (p34), RINT-1, ANAPC7, Ubiquitin, FHIT, CDC23, Cyclin A1, Shc, CKS1, TRF1, FANCD2, ATM, AKT3, MRLC, Lamin B1, TCP1-epsilon, BUBR1, TOP2 alpha, CAP-H/H2, LATS2, Lamin B, IGF-1 receptor, GADD45 alpha, Cyclin A, CNAP1, PCTK1, TOP2, AKT(PKB), ZAK, 14-3-3 eta, Dynamin, BRRN1, p38gamma (MAPK12), Cyclin B1, p53, Emi1, p38 MAPK, PKA-cat (CAMP-dependent), MAT1, Histone H1

RFC4, Chk2, OGG1, NEIL3, NFBD1, Brca1, PARP-1, HUS1, MBD4, NEIL1, ERCC6, Rad50, DNA polymerase beta, POLE2, XPF, FEN1, DNA ligase I, RFC5, TFIIH p52 subunit, TDG, TFIIH p34 subunit, PCNA, UNG1, PARP-2, MRE11, DDB2, RFC3, RAD23B, MRN complex, RAD1, POLD reg (p68), ATM, PARG, POLE3-POLE4 complex, RFC1, RFC2, Brca1/Bard1, PARP-3, POLE3 (YBL1), p53, RFC complex, Bard1, Nibrin, MBD1, XPD, RPA2, MAT1, TFB5

Tubulin beta, Tiam1, VE-cadherin, BPAG2, N-cadherin, E-cadherin, ITGB1, 14-3-3 epsilon, Cingulin, MUPP1, Tcf(Lef), ZO-1, Fer, ERK1/2, Keratin 5, 14-3-3, Claudin-16, Beta-catenin, Nectin-2, BPAG1, DLG5(P-dlg), Connexin 46, Claudin-8, Desmoglein 3, Vimentin, Actin, Paxillin, MAGI-1(BAIAP1), GIT1, PI3K reg class IA (p85), JAM3, ATP1B1, Tubulin alpha, Desmocollin 3, R-cadherin, PKC, PLC-beta, Endothelin-1, CASK, Keratin 18, Desmoglein 2, Beta-fodrin, Claudin-7, Itch, PLC-gamma, Keratin 8/18, Claudin-4, SIP1 (ZFHX1B), Nectin-3, Desmoplakin, Keratin 8, ZO-3, PSD-95, Keratin 6A, PEZ, ERK2 (MAPK1), Caveolin-1, 14-3-3 eta, Claudin-3, PARD6, Connexin 31, Tubulin (in microtubules) CENP-A, MCM4, MCM10, ORC3L, MAD2a, CENP-H, Cyclin D, Rod, Kid, CDC25A, ORC6L, ASK (Dbf4), FEN1, DNA ligase I, p21, BUB1, DNA polymerase alpha/primase, Aurora-A, Securin, CDK1 (p34), Cyclin E2, CDC18L (CDC6), Survivin, BUBR1, MCM6, Cyclin A, Cyclin D1, HEC, TOP2, Cdt1, Cyclin B1, p16INK4, Emi1, RPA2, Zwilch, MAT1, CDC45L

RACK1, WNT4, VE-cadherin, BPAG2, N-cadherin, E-cadherin, ITGB1, PCDHA6, PCDHA4,
VLDLR, Tcf(Lef), EGFR, Ski, ZO-1, Presenilin 1, Fer, DKK1, PCDHGC3, Casein kinase I epsilon, Beta-catenin, Nectin-2, H-cadherin, PTPR-mu, SSX2IP, BPAG1, DLG5(P-dlg), PCDHGB2, Desmoglein 3, Actin, CTNNAL1, Protocadherin 18, PCDHGA3, Shc, PI3K reg class IA (p85), PCDA7, Desmocollin 3, R-cadherin, MTSS1, Cadherin 10, FAT1, PKC, PCDHGA1, FHL2, PKC-alpha, Protocadherin gamma B1, Desmoglein 2, WNT, WNT10B, EVL, Nectin-3, LRP6, Axin2, Casein kinase I, PCDHGA12, Fyn, Vinexin, DAB1, PEZ, AKT (PKB), PDZK3, PCDHGB4, Axin, PTPR-zeta, Frizzled, Tubulin (in microtubules) 


\section{Table 2 Enrichment analysis report by process networks (Continued)}

\begin{tabular}{|c|c|c|c|}
\hline 9 & $\begin{array}{l}\text { Proteolysis ubiquitin- } \\
\text { proteasomal proteolysis }\end{array}$ & 0.0000769830526795964 & $\begin{array}{l}\text { MDM4, HAUS7, Brca1, PSMB8(LMP7), KEAP1, PSMA4, Cullin 2, c-Cbl, UBCH7, UCHL3, } \\
\text { SAE1/2, TGT, PSMB1, PSMC3, PSMC6, PSMD5, PSMA7, PSMC4, SENP2, SAE1, GRAIL, } \\
\text { PSMD10 (Gankyrin), PSME1, DTX3, Ubiquitin, PSMD3, PSMD2, RAD23B, NF-X1, PSMB6, } \\
\text { MUF1, PSME2, PSMD8, PSMD7, Syntaxin 5, Itch, Elongin C, MPDZ, NEDD4L, MDM2, } \\
\text { DORFIN, PSMB3, UBC7, PSMD14, Brca1/Bard1, RING-box protein 1, PSMB7, PSMD12, } \\
\text { PSMA3, PSMC5, BAG-1, PSMA5, HSP70, p47, Bard1, PSMA6, PSMA2, PSMD6, PSMC1, } \\
\text { MMS2 }\end{array}$ \\
\hline 10 & $\begin{array}{l}\text { Cytoskeleton spindle } \\
\text { microtubules }\end{array}$ & 0.00008172060696576 & $\begin{array}{l}\text { Tubulin beta, Tubulin gamma, KIF4A, HZwint-1, Cyclin B, HOOK1, Cyclin B2, ZW10, } \\
\text { Nek2A, Tubulin alpha 1A, CENP-A, Tubulin delta, MAD2a, CENP-H, Importin } \\
\text { (karyopherin)-alpha, Rod, RCC1, MKLP2, Kid, BUB1, Sororin, Aurora-A, Securin, CDK1 } \\
\text { (p34), ANAPC7, Tubulin alpha, Dynein 1, cytoplasmic, heavy chain, Karyopherin alpha } \\
\text { 2, 4.1N, DLC1 (Dynein LC8a), BUBR1, DORFIN, DEEPEST, MID1, EML4, HEC, TTK, MCAK, } \\
\text { Cyclin B1, PAFAH alpha (LIS1), RAE1, Zwilch, Tubulin (in microtubules) }\end{array}$ \\
\hline
\end{tabular}

Table 3 Deregulated centrosome genes

\begin{tabular}{|c|c|c|}
\hline Gene symbol & Gene name & HCC1954/MCF10A \\
\hline PLK2 & polo-like kinase 2 & 5.82 \\
\hline SGOL1 & shugoshin-like 1 (S. pombe) & 4.24 \\
\hline CETN2 & centrin, EF-hand protein, 2 & 4.12 \\
\hline AURKA & aurora kinase $\mathrm{A}$ & 4.01 \\
\hline BRCA1 & breast cancer 1 , early onset & 3.77 \\
\hline CDK1 & cyclin-dependent kinase 1 & 3.50 \\
\hline SON & SON DNA binding protein & 3.09 \\
\hline NEK2 & NIMA (never in mitosis gene a)-related kinase 2 & 2.89 \\
\hline RANBP1 & RAN binding protein 1 & 2.82 \\
\hline CEP76 & centrosomal protein $76 \mathrm{kDa}$ & 2.46 \\
\hline GADD45A & growth arrest and DNA-damage-inducible, alpha & 2.40 \\
\hline TMEM67 & transmembrane protein 67 & 2.40 \\
\hline TBCCD1 & TBCC domain containing 1 & 2.36 \\
\hline SASS6 & spindle assembly 6 homolog (C. elegans) & 2.33 \\
\hline UXT & ubiquitously-expressed, prefoldin-like chaperone & 2.27 \\
\hline XPO1 & exportin 1 (CRM1 homolog, yeast) & 2.13 \\
\hline HAUS2 & HAUS augmin-like complex, subunit 2 & 2.13 \\
\hline CEP192 & centrosomal protein $192 \mathrm{kDa}$ & 2.03 \\
\hline HAUS7 & HAUS augmin-like complex, subunit 7 & 2.03 \\
\hline SPICE1 & spindle and centriole associated protein 1 & 2.01 \\
\hline CTNNB1 & catenin (cadherin-associated protein), beta 1, $88 \mathrm{kDa}$ & 1.88 \\
\hline HAUS5 & HAUS augmin-like complex, subunit 5 & 1.65 \\
\hline PAFAH1B1 & platelet-activating factor acetylhydrolase $1 \mathrm{~b}$, regulatory subunit 1 (45 kDa) & 1.50 \\
\hline NDEL1 & nudE nuclear distribution E homolog (A. nidulans)-like 1 & -1.50 \\
\hline ARHGEF10 & Rho guanine nucleotide exchange factor (GEF) 10 & -1.76 \\
\hline PKD2 & polycystic kidney disease 2 (autosomal dominant) & -1.80 \\
\hline PCM1 & pericentriolar material 1 & -1.82 \\
\hline CEP250 & centrosomal protein $250 \mathrm{kDa}$ & -1.89 \\
\hline PLXNA2 & plexin A2 & -3.92 \\
\hline SEMA6A & sema domain, transmembrane domain (TM), and cytoplasmic domain, (semaphorin) 6A & -6.99 \\
\hline
\end{tabular}


different Her2+ cell lines (Table 4). Semi-quantitative PCR analysis validated the differential expression for most genes downregulated in HCC1954 cells (Figure 1A) and for some genes upregulated in this cell line (Figure $1 \mathrm{C}$ ). Consistent with this finding, similar trends were found by real-time PCR analysis (Figure 1B,D). The results show that, compared to MCF10A control, MDM2 and PlexinA2 were significantly downregulated in JIMT-1 and in HCC1954 cells. On the other hand, C-Nap1 and SFRP1 RNA levels were significantly increased in JIMT-1 cells compared to MCF10A cells. Among the upregulated genes in HCC1954 cells, AURKA, CETN2 and GINS2 RNA levels were significantly increased compared to MCF10A and all of the genes investigated, with the exception of SAS6 and SPICE, were more highly upregulated in JIMT-1 cells than in HCC1954 cells. These data validated our microarray analysis and confirmed differences of molecular signatures between two Her2+ breast cancer cell lines.

\section{Transient knockdown of SEMA6A or MDM2 and} centrosome amplification in MCF10A cells

After the real-time PCR validation of the microarray targets, we chose to further pursue three genes; MDM2, SEMA6A and SFRP1 that were downregulated in HCC1954 cells, based on the relevance and novelty of their function in centrosome duplication. First, we investigated protein expression by Western blot (Figure 2A). Both SEMA6A and SFRP1 protein levels were highly decreased in three Her2+ cell lines, HCC1954, JIMT-1 and SKBR3 compared to nontransformed normal epithelial MCF10A cells. However, unlike real-time PCR data, MDM2 protein levels across the three Her2+ cell lines were comparable to those of MCF10A cells. Since two of these proteins were less abundant in breast cancer cells, we speculated that at high levels, these molecules would represent suppressors of CA. To test this possibility, we proceeded to knock these genes down in MCF10A cells using siRNAs to test whether their downregulation induces CA. As illustrated in Figure 2B, we were able to effectively knockdown both MDM2 and SFRP1 with two independent sequences targeting different regions of the genes. However, we did not achieve knockdown of SEMA6A using the same strategy; thus, we eliminated this gene from further experiments. Even though both siRNA sequences significantly decreased MDM2 and SFRP1 protein levels in MCF10A cells, only one duplex for each gene (MDM2_1, SFRP1_3) induced CA (Figure 2). Similar results were obtained for the BrdU incorporation assay, since only one sequence (MDM2_1, SFRP1_2, respectively) decreased the extent of BrdU incorporation.

\section{Transient knockdown of SGOL1 or TTK decreases centrosome amplification in Her2+ cells}

From the subset of genes that were upregulated in HCC1954 cells compared to MCF10A cells, we chose shugoshin 1 (SGOL1) and TTK, based on their relevance and novelty, since the centrosome roles of these genes are not fully understood, especially in cancer models. We predicted that their gene products are required for $\mathrm{CA}$ and proceeded to silence them in order to address whether their silencing would diminish percentages of

Table 4 Differential expression of selected cell cycle and centrosome genes

\begin{tabular}{|c|c|c|c|c|}
\hline \multirow[t]{2}{*}{ Accession number } & \multirow[t]{2}{*}{ Genes down regulated in breast cancer cells } & \multirow[t]{2}{*}{ Metacore fold change } & \multicolumn{2}{|c|}{ Fold changes, real-time PCR } \\
\hline & & & HCC1954 & JIMT-1 \\
\hline [GenBank: NM_012395] & CDK14 & 14.26 & $0.53 \pm 0.48$ & $1.19 \pm 0.23$ \\
\hline [GenBank:NM_014865.3] & C-Nap1 & 1.89 & $0.90 \pm 0.18$ & $3.13 \pm 0.27$ \\
\hline [GenBank:NM_002392] & MDM2 & 3.18 & $0.04 \pm 0.01$ & $0.28 \pm 0.13$ \\
\hline [GenBank:NM_025179] & Plexin A2 & 3.92 & $0.37 \pm 0.07$ & $0.04 \pm 0.01$ \\
\hline [GenBank:NM_020796] & Semaphorin $6 \mathrm{~A}$ & 6.99 & $0.01 \pm 0.01$ & $0.04 \pm 0.01$ \\
\hline \multirow[t]{2}{*}{ [GenBank:NM_003012] } & SFRP1 & 38.04 & $0.00 \pm 0.00$ & $1.96 \pm 0.07$ \\
\hline & Genes up regulated in breast cancer cells & & & \\
\hline [GenBank:NM_003318] & TTK & 4.62 & $2.10 \pm 1.11$ & N/A \\
\hline [GenBank:NM_198433] & Aurora-A kinase & 4.01 & $5.14 \pm 0.91$ & $3.2 \pm 0.46$ \\
\hline [GenBank:NM_001786] & CDK1 & 3.5 & $1.06 \pm 0.37$ & $2.85 \pm 0.65$ \\
\hline [GenBank:NM_032142] & CEP192 & 2.03 & $2.03 \pm 0.81$ & $4.36 \pm 0.55$ \\
\hline [GenBank:NM_004344] & Centrin-2 & 4.12 & $2.42 \pm 0.30$ & $4.77 \pm 1.27$ \\
\hline [GenBank:NM_016095] & GINS2 & 11.49 & $4.76 \pm 1.59$ & $1.41 \pm 0.04$ \\
\hline [GenBank:NM_004850] & ROCK2 & $<1.5$ & $1.46 \pm 0.61$ & $4.41 \pm 0.70$ \\
\hline [GenBank:NM_194292] & SASS6 & 2.33 & $1.33 \pm 0.36$ & $2.13 \pm 0.41$ \\
\hline [GenBank:NM_144718] & SPICE1 & 2.01 & $2.50 \pm 0.87$ & $2.45 \pm 1.11$ \\
\hline [GenBank:NM_001012410] & SGOL1 & 4.24 & $1.49 \pm 0.46$ & $3.88 \pm 0.26$ \\
\hline
\end{tabular}




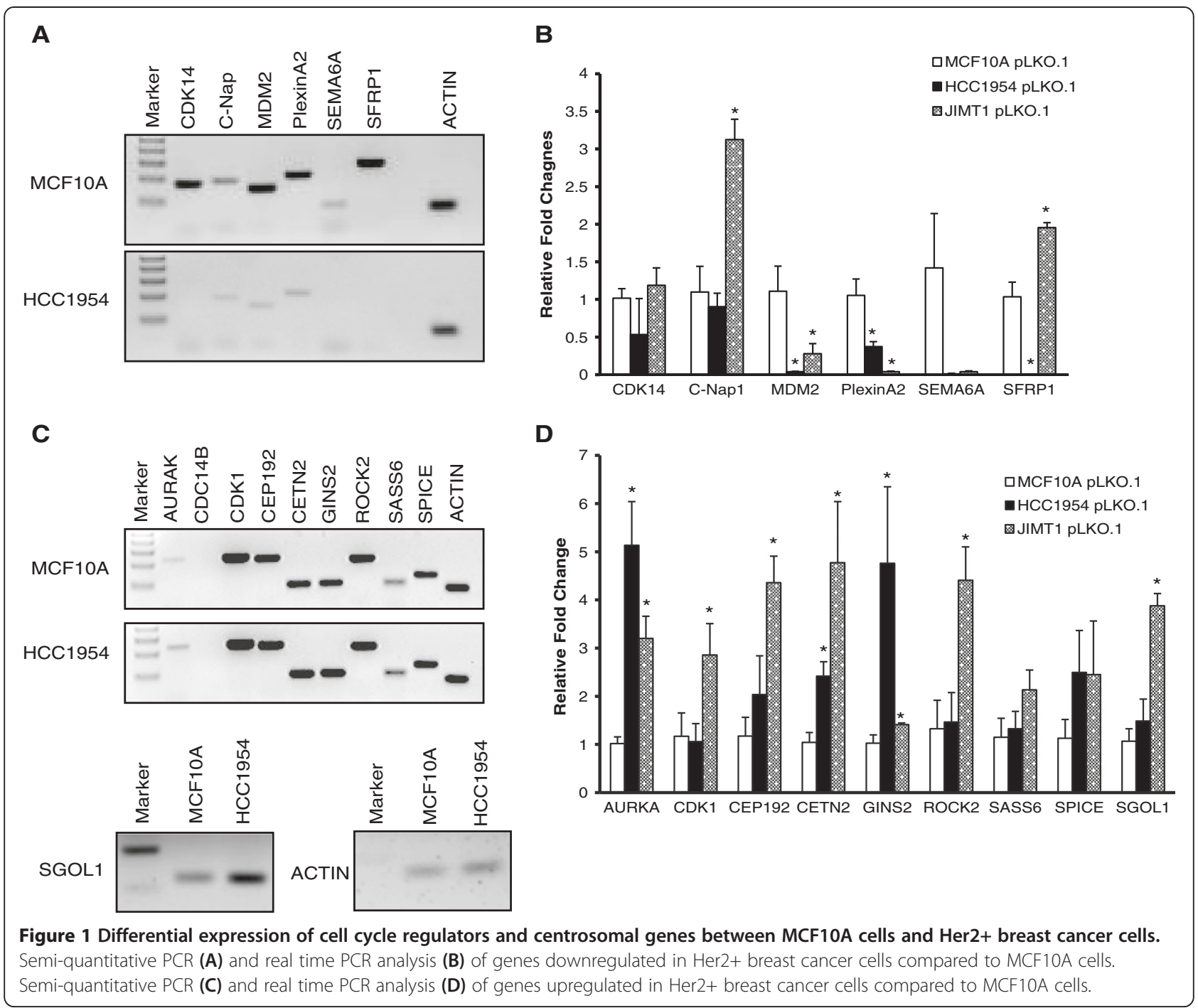

CA in Her2+ breast cancer cells. Western blot analysis shown in Figure 3A confirmed that protein levels of SGOL1 and TTK were much higher in unsynchronized populations of Her2+ cell lines compared to MCF10A cells. Next, we transiently knocked down both proteins by using at least two independent siRNA duplexes, achieving total silencing with SGOL1_1 and partial downregulation with SGOL1_2 (Figure 3B). Knockdown of SGOL1 with SGOL1_1 decreased the percentages of CA in both HCC1954 and JIMT-1 cell lines compared to scrambled negative control and the same clone reduced percentages of BrdU + cells in JIMT-1 cells (Figure 3C,D). Knockdown of TTK with two independent siRNA sequences reduced the percentages of CA in HCC1954 cells (Figure 3C) and modestly affected BrdU incorporation (Figure 3D). These data suggest that reduced CA detected in HCC1954 and JIMT-1 cells by transient knockdown of SGOL1 may derive from the reduced DNA replication. However, the reduction in CA observed after transient knockdown of TTK is due to a mechanism apart from changes in DNA replication.

\section{Association of MDM2, SFRP1, and TTK expression with the outcome of breast cancer patients}

To explore the clinical relevance of the target genes, we used the http://kmplot.com/analysis/ resource that provides an online survival analysis tool to rapidly assess the effect of 22,277 genes on breast cancer prognosis using microarray data of 1809 patients [20]. We found that MDM2 and SFRP1 transcripts were positively correlated with relapse free survival for all breast cancer subtypes and the results were statistically significant (Figure 4A,B). In the case of TTK, RNA level was negatively correlated with overall survival of luminal A breast cancer patients, showing statistical significance (Figure 4C). However, no public survival data were available for SGOL1. 


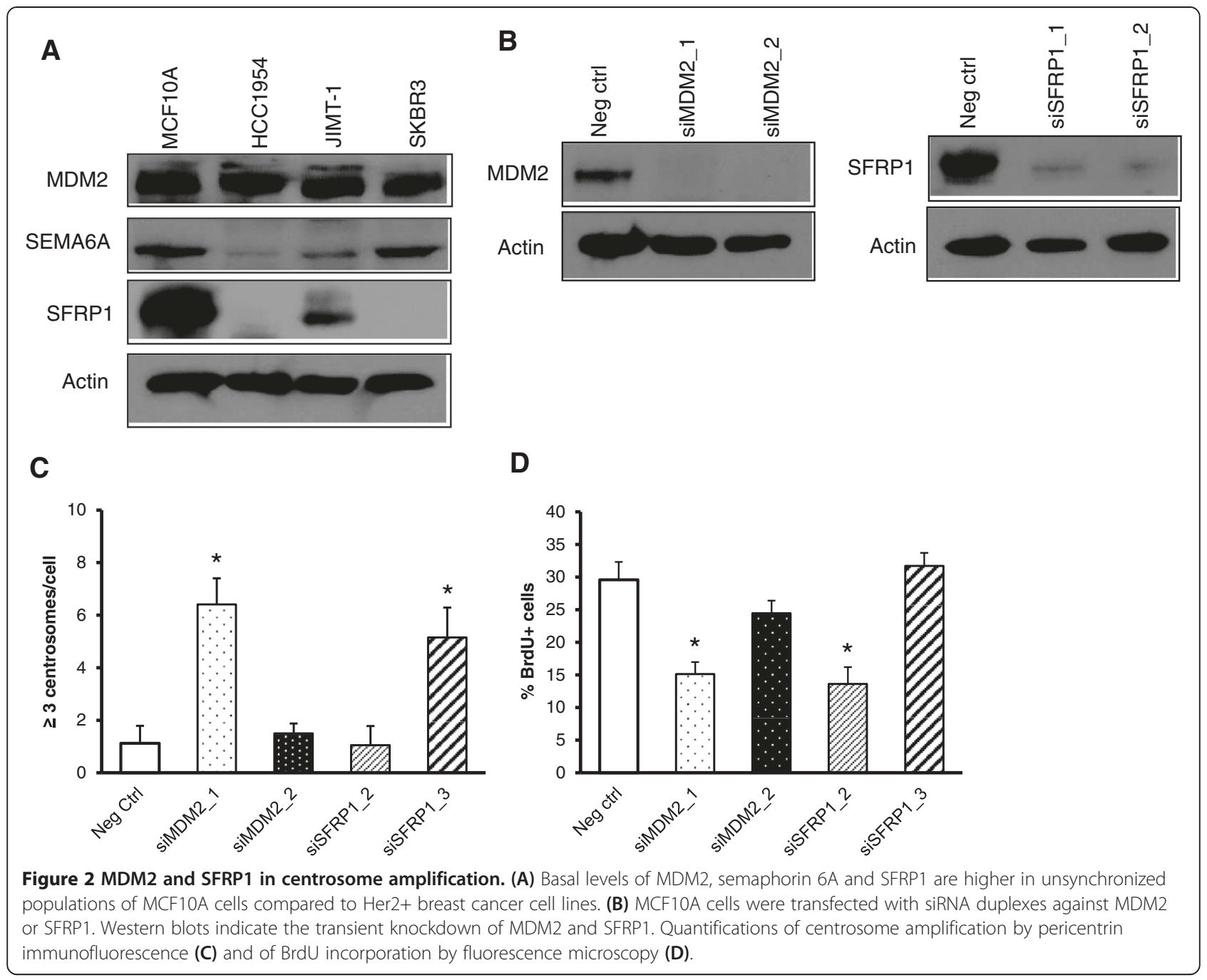

\section{Discussion}

Centrosome amplification (CA) is a precursor of chromosome instability and polyploidy and may facilitate the acquisition and maintenance of several malignant phenotypes in breast tumors. Previously, we screened breast cancer cell lines of various subtypes to find an accurate model for CA studies and found three Her2+ cell lines; HCC1954, JIMT1 and SKBR3 that displayed significant CA compared to MCF10A non-tumorigenic epithelial cells $[4,16]$. To seek out new targets differentially expressed in these cell lines, thereby potentially modulating the extent of $\mathrm{CA}$, we performed a microarray based on Affymetrix platform using MCF10A cells and HCC1954 cells as a starting point and explored several selected targets by real time PCR and Western blots.

Amongst the differentially expressed genes, we identified downregulation of secreted frizzled-related protein1 (SFRP-1) in three Her2+ breast cancer cell lines. SFRPs are inhibitory WNT family members that block the WNT signaling pathway and the competition between
Frizzled and SFRP1 for binding to WNT regulates the pathway activation [21]. There is a plethora of evidence of loss of SFRP1 expression in many cancers including breast cancer [22-25], suggesting that this gene acts as a mammary tumor suppressor. SFRP1 is expressed in the normal breast epithelium and its expression is lost in more than $80 \%$ of invasive breast carcinomas [26]. In a mouse model, 10 week old nulliparous SFRP1-/- animals showed inappropriate mammary gland development relative to controls, evidenced by extensive branching with clear lobulo-alveolar development, along with a significantly higher density of ducts with distinct alveoli present throughout the mammary gland [27]. More recently, Matsuda et al showed that ectopic expression of SFRP1 in MDA-MB-231 triple negative breast cancer cells blocks canonical WNT signaling and decreases their migration potential and cell proliferation in a xenograft model along with dramatically impairing lung metastases [28]. Another relevant study showed that triple negative breast cancer cells treated with HDAC inhibitor romidepsin and 
A

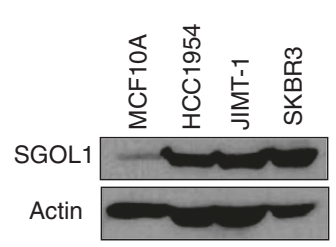

B

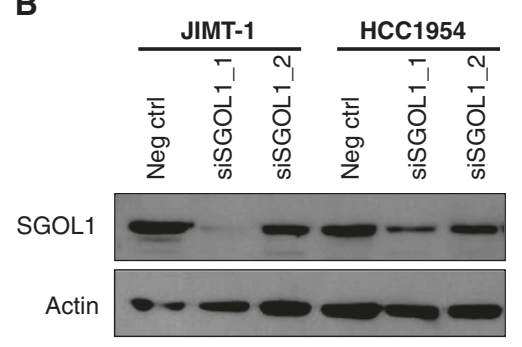

C

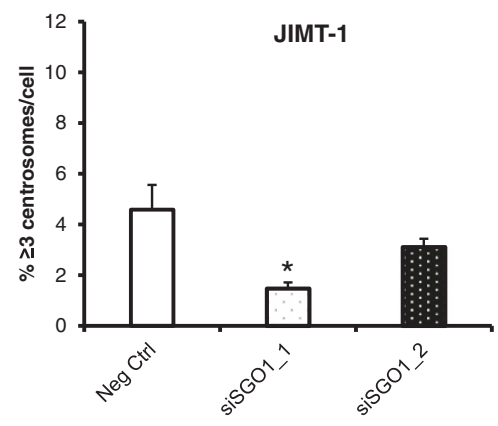

D

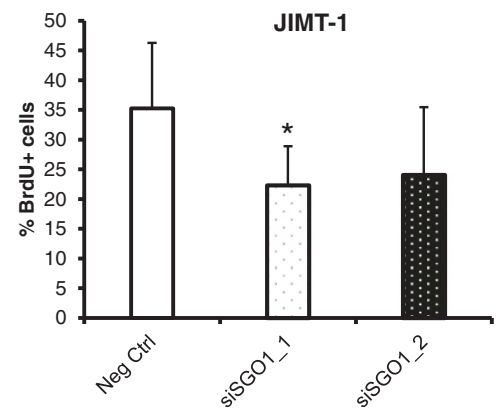

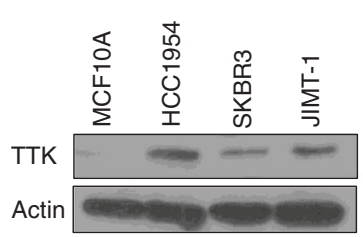

HCC1954
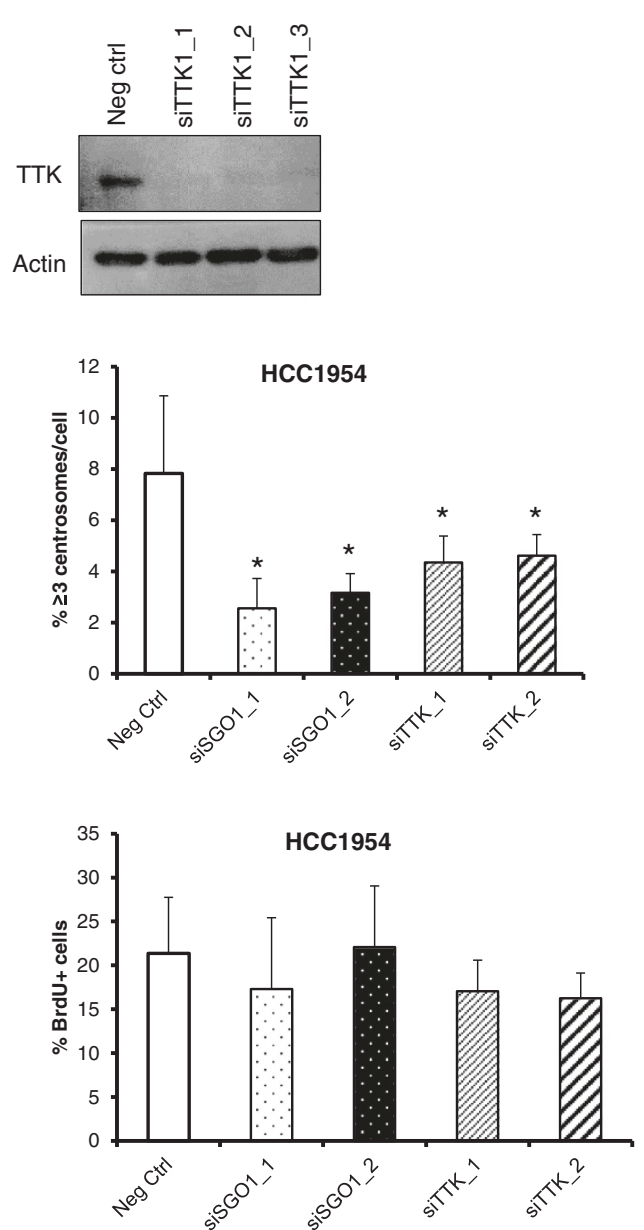

Figure 3 Shugoshin 1 and TTK maintain centrosome amplification in Her2+ breast cancer cells. (A) Basal levels of SGOL1 and TTK are higher in unsynchronized populations of Her2+ breast cancer cell lines compared to MCF10A cells. JIMT-1 cells were transfected with siRNA duplexes against SGOL1 and HCC1954 cells were transfected with siRNA against SGOL1 or TTK. (B) Western blots indicating the transient knockdown of SGOL1 in JIMT-1 and HCC1954 cells (left) and TTK in HCC1954 cells (right). Quantifications of fluorescent microscopy for centrosome amplification by pericentrin staining (C) and of BrdU incorporation (D).

methyltransferase inhibitor decitabine induced reexpression of SFRP1, along with synergistic inhibition of cell growth and induction of apoptosis [29]. To date, there have been no reports about the function of SFRP1 in regards to CA. In this study, we show that in normal epithelial MCF10A cells, SFRP1 knockdown with siRNA sequences did not consistently induce CA.

MDM2, mouse double minute 2 homolog, first identified as an inhibitor of p53 transcriptional activation [30], is an E3 ubiquitin ligase that targets p53 degradation, thereby keeping p53 levels and activity low in unstressed cells [31]. The molecular significance of MDM2 stems from its ability to interact with more than 100 molecules [32]. For instance, activation of E2F1 is stimulated by its binding to MDM2 [33]. Amplification or altered expression of MDM protein has been found in many tumors [34-36]. In terms of its breast cancer-promoting properties, Smad3/4 transcription factors activated by TGF- $\beta 1$ bind to the promoter region of MDM2 to increase its protein expression [37]. As a result, upon TGF- $\beta 1$ treatment, 


\section{A}

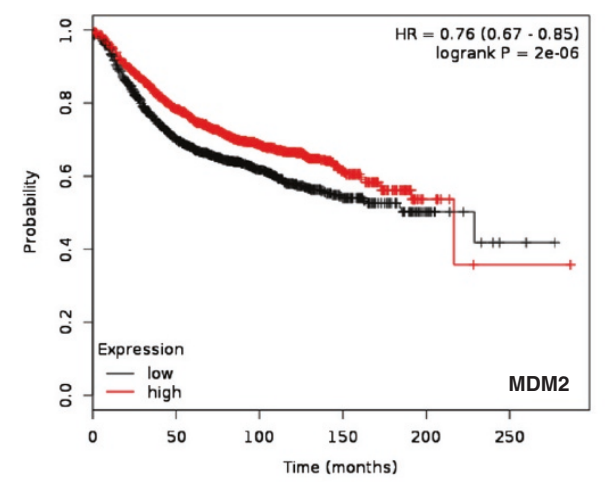

C

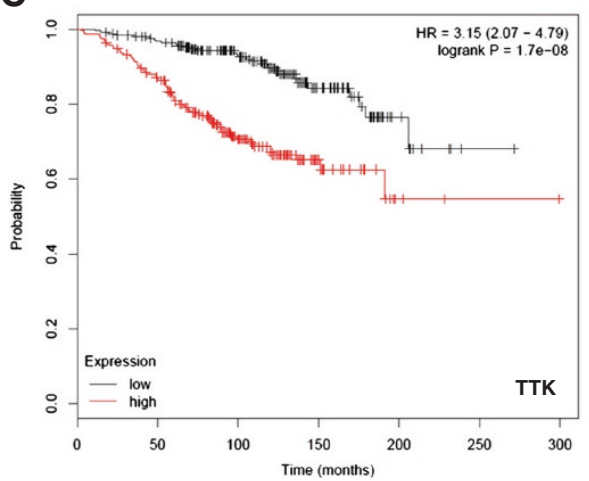

B

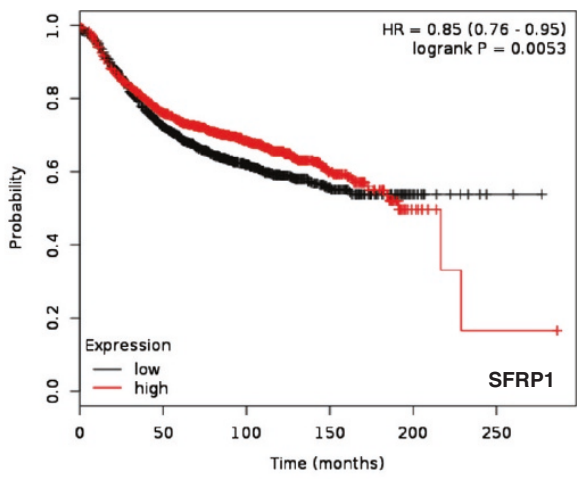

Figure 4 Correlations between the levels of MDM2, SFRP1 or TTK and survival of breast cancer patients. (A) Kaplan-Meier curve for MDM2 expression and relapse-free survival of breast cancer patients of all subtypes. (B) Kaplan-Meier curve for SFRP1 expression and relapse-free survival of breast cancer patients of all subtypes. (C) Kaplan-Meier curve for TTK expression and overall survival of luminal A breast cancer patients.

the murine mammary epithelial cells NMuMg undergo the epithelial to mesenchymal transition and are able to migrate. Also, MDM2 overexpression in MCF-7 (estrogen receptor positive, Her2-negative) and MDA-MB-231 (triple-negative) cell lines promotes invasion and metastasis in invasive ductal breast carcinoma by upregulating matrix metalloproteinase-9 [38]. There have been a handful of reports about overexpression of MDM2 and CA, but never one that addresses the effects of its downregulation and CA. For example MDM2 overexpression promotes CA in tumors that retain wild-type p53 [39]. However, later studies showed that the functions of MDM2 in inducing genomic instability and transformation could also be p53-independent [40-43]. Our validated microarray revealed highly decreased mRNA levels of MDM2 in Her2+ cells compared to MCF10A but MDM2 protein level was not diminished. Similar to SFRP1, knockdown of MDM2 with siRNA did not consistently induce CA. In this report, we found that lower MDM2 mRNA expression negatively correlates with disease-free survival. In summary, the mechanisms responsible for the acquisition of SFRP1 or MDM2mediated CA need to be further investigated and one interesting aspect is whether SFRP1 or MDM2 overexpression in Her2+ cells decreases CA.

From the 2635 genes overexpressed in HCC1954 Her2+ breast cancer cells versus non-tumorigenic control and following downstream analyses, shugoshin 1 and TTK piqued our interest. These genes are of interest due to potential diverse functions associated with chromosome segregation, spindle formation and centrosome cycle. The impact of these genes on CA is also unclear and controversial. We did not study Aurora A kinase, the top centrosome upregulated gene, since Aurora A overexpression is known to promote CA $[44,45]$. Likewise, Nek2 is another kinase we did not address, since our previous publications indicate it maintains CA and CIN in Her2+ breast cancer cells $[15,16]$ and in MCF10A cells expressing H-Ras ${ }^{\text {G12V }}$ or H-Ras ${ }^{G 12 \mathrm{~V}}$ and c-Myc [46]. Shugoshin proteins (SGOL1 and SGOL2) prevent the cleavage of cohesion complexes localized around sister chromatids by separase from $\mathrm{S}$ phase to metaphase. In vertebrates, this function is probably achieved via the interaction between SGOL1 and the PP2A phosphatases that counteract the phosphorylation of cohesion subunits $[47,48]$. SGOL1 interacts with the spindle assembly checkpoint (SAC) kinase Bub1 and this 
interaction is required for the centromere localization of shugoshin [49-52]. Centromeric localization of SGOL1 is also promoted by the interaction with Aurora B kinase of the chromosomal passenger complex (CPC) [52]. Finally, because of phosphorylation by Nek2, SGOL1 integrates the centromeric cohesion and spindle attachment at the kinetochore [53]. Although not very abundant, the current literature clearly points out that shugoshin can accomplish multiple functions, such as chromatid and centriole cohesion or spindle assembly. Therefore, SGOL1 is crucial for chromosome segregation and mitotic progression and its deregulation can have detrimental effects including centrosome amplification, chromosome instability, and aneuploidy. Depletion of SGOL1 precludes viability as demonstrated by Sgol 1 knockout mouse studies [50]. Overexpression of SGOL1 was detected in the sera of breast cancer patients [54] and has been associated with additional human cancers, including gastric, colorectal, AML and NSCLC [48,55-57]. In stark contrast with these clinical correlations, another study in colorectal cancer found low levels of SGOL1 in tumor samples while in cell culture SGOL1 knockdown induced CA, CIN and mitotic catastrophe [58]. A genome-wide RNAi array performed in oral squamous cancer cells detected SGOL1 as one of the molecules implicated in centrosome clustering [59]. This is a phenomenon that typically occurs in cells with amplified centrosomes and leads to the formation of pseudopolar spindles and bipolar division, as opposed to mitotic multipolar spindles that cause cell death [10]. Various functional assays demonstrated that transient silencing of SGOL1 resulted in mitotic arrest, multipolar spindles, reduced spindle tension, and cell death [59]. This seminal work showing that depletion of SGOL1 inhibits centrosome clustering is consistent with our data confirming a linear correlation between the extent of SGOL1 knockdown and the decrease of centrosome amplification, as measured by pericentrin labeling, and also a correlation with decreased DNA synthesis. Our findings presented here represent the first evidence of the biological relevance of SGOL1 in a breast cancer cell model and the first indication that its overexpression promotes CA. In conclusion, the versatile SGOL1 protein may coordinate critical interactions involving the spindles and chromosome biology. As a result, deregulated SGOL1 localization and function in breast cancer cells can significantly contribute to the acquisition of CA, centrosome clustering, chromosome missegregation and instability and aneuploidy. Based on this evidence, SGOL1 is an attractive target for blocking the progression of genomically unstable breast tumors that display CA. However, the molecular biology underlying the centrosome and centromere functions of SGOL1 awaits more studies.

TTK, also known as monopolar spindle 1 , is a dual specificity kinase with well characterized roles in the spindle assembly checkpoint [60]. In addition to its function during mitosis, TTK has also shown a role in centriole duplication and assembly [61,62]. Proper levels and regulation of TTK are partially responsible for ensuring accurate centriole duplication and assembly during the cell cycle [63]. One mechanism which prevents TTK accumulation from resulting centriole re-duplication is through control of TTK levels via the MPS1 degradation signal [62]. Although TTK may not be required for normal centriole duplication, several studies support the notion that overexpressed TTK results in centriole reduplication, which could lead to CA. In breast cancer, increased TTK mRNA levels have been noted across many cell lines, specifically Her2+ and triple negative subtypes and in tumor samples collected from patients with advanced disease [64-66]. These correlations suggest an association between TTK levels and cancer behavior (i.e. cell proliferation, tumor aggressiveness). Thus, TTK presents a potential biomarker to predict patient prognosis in breast cancer or as a useful drug target for a subset of breast cancers. Previous studies have revealed how modifying TTK expression levels affects cell viability, mitosis and tumor growth in vivo but none have addressed TTK's functional roles involved with CA in breast cancer [64,65]. In this report, we show for the first time that attenuating TTK levels can decrease the percentages of CA observed in a subset of Her2+ breast cancer cells without affecting the integrity of DNA synthesis. Further dissection of the mechanism for how TTK can drive CA and genomic instability in specific breast cancer subtypes will be a key to understanding the correlations between high TTK levels and more aggressive/drug resistant breast tumors.

\section{Abbreviations \\ CA: Centrosome amplification; CIN: Chromosome instability; ER: Estrogen receptor; PR: Progesterone receptor; DCIS: Ductal carcinoma in situ; MDM2: Mouse double minute 2 homolog; SFRP1: Secreted frizzled-related protein 1; SGOL1: Shugoshin-like 1; BrdU: 5-bromo-2-deoxyuridine; DAPI: 4',6-diamidino-2-phenylindole; GO: Gene ontology; AML: Acute myeloid leukemia; NSCLC: Non-small cell lung cancer.}

\section{Competing interests}

The authors declare that they have no competing interests.

\section{Authors' contribution}

ML: Performed semi-quantitative and real-time PCR, siRNA knockdown of SFRP1 and MDM2, CA and BrdU assays and wrote part of manuscript. MM: Analyzed normalized microarray data, performed GO analysis, siRNA knockdown of SGOL1, CA and BrdU assays and wrote part of manuscript. JLK: Performed TTK real-time PCR, siRNA knockdown of TTK, CA and BrdU assays and wrote part of the manuscript. HIS: Designed the project and edited the manuscript. All authors read and approved the final manuscript.

\section{Acknowledgements}

We would like to thank Khanjan Gandhi and Dr. Jeanne Kowalski from the Biostatistics and Bioinformatics Shared Resource, Winship Cancer Institute for the assistance with the microarray data acquisition and normalization. Research reported in this publication was supported by the Integrated Cellular Imaging (ICl) Shared Resource of Winship Cancer Institute of Emory University and $\mathrm{NIH} / \mathrm{NCl}$ under award number P30CA138292 and by R01 CA151521 from the National Institutes of Health. The content is solely the 
responsibility of the authors and does not necessarily represent the official views of the National Institutes of Health.

\section{Author details}

'Department of Radiation Oncology, Winship Cancer Institute, Emory University School of Medicine, C3084, 1365C Clifton Road NE, Atlanta, GA 30322, USA. ${ }^{2}$ Cancer Biology Graduate Program, Emory University School of Medicine, 1365C Clifton Road NE, Atlanta, GA 30322, USA.

Received: 29 July 2014 Accepted: 8 September 2014

Published: 25 September 2014

\section{References}

1. Roylance R, Endesfelder D, Gorman P, Burrell RA, Sander J, Tomlinson I, Hanby AM, Speirs V, Richardson AL, Birkbak NJ, Eklund AC, Downward J, Kschischo M, Szallasi Z, Swanton C: Relationship of extreme chromosomal instability with long-term survival in a retrospective analysis of primary breast cancer. Cancer Epidemiol Biomarkers Prev 2011, 20:2183-2194.

2. Fukasawa K: Oncogenes and tumour suppressors take on centrosomes. Nat Rev Cancer 2007, 7:911-924.

3. Harrison MK, Adon AM, Saavedra HI: The G1 phase Cdks regulate the centrosome cycle and mediate oncogene-dependent centrosome amplification. Cell Div 2011, 6:2.

4. Marina M, Saavedra HI: Nek2 and Plk4: prognostic markers, drivers of breast tumorigenesis and drug resistance. Front Biosci (Landmark Ed) 2014, 19:352-365.

5. Wang S, Li W, Liu N, Zhang F, Liu H, Liu F, Liu J, Zhang T, Niu Y: Nek2A contributes to tumorigenic growth and possibly functions as potential therapeutic target for human breast cancer. J Cell Biochem 2012, 113:1904-1914.

6. Lee J, Gollahon L: Mitotic perturbations induced by Nek2 overexpression require interaction with TRF1 in breast cancer cells. Cell Cycle 2013, 12:3599-3614

7. Godinho SA, Picone R, Burute M, Dagher R, Su Y, Leung CT, Polyak K, Brugge JS, Thery M, Pellman D: Oncogene-like induction of cellular invasion from centrosome amplification. Nature 2014, 510:167-171.

8. Adon AM, Zeng X, Harrison MK, Sannem S, Kiyokawa H, Kaldis P, Saavedra $\mathrm{HI}: \mathrm{Cdk} 2$ and Cdk4 regulate the centrosome cycle and are critical mediators of centrosome amplification in p53-null cells. Mol Cell Biol 2010, 30:694-710.

9. Tarapore P, Horn HF, Tokuyama Y, Fukasawa K: Direct regulation of the centrosome duplication cycle by the p53-p21Waf1/Cip1 pathway. Oncogene 2001, 20:3173-3184.

10. Godinho SA, Kwon M, Pellman D: Centrosomes and cancer: how cancer cells divide with too many centrosomes. Cancer Metastasis Rev 2009, 28:85-98.

11. Guo HQ, Gao M, Ma J, Xiao T, Zhao LL, Gao Y, Pan QJ: Analysis of the cellular centrosome in fine-needle aspirations of the breast. Breast Cancer Res 2007, 9:R48.

12. Schneeweiss A, Sinn HP, Ehemann V, Khbeis T, Neben K, Krause U, Ho AD, Bastert G, Kramer A: Centrosomal aberrations in primary invasive breast cancer are associated with nodal status and hormone receptor expression. Int I Cancer 2003, 107:346-352.

13. Lingle WL, Lutz WH, Ingle JN, Maihle NJ, Salisbury JL: Centrosome hypertrophy in human breast tumors: implications for genomic stability and cell polarity. Proc Natl Acad Sci U S A 1998, 95:2950-2955.

14. Lingle WL, Salisbury JL: Altered centrosome structure is associated with abnormal mitoses in human breast tumors. Am J Pathol 1999, 155:1941-1951.

15. Harrison Pitner MK, Saavedra HI: Cdk4 and nek2 signal binucleation and centrosome amplification in a her $2+$ breast cancer model. PLoS One 2013, 8:e65971.

16. Lee MY, Moreno CS, Saavedra HI: The E2F activators signal and maintain centrosome amplification in breast cancer cells. Mol Cell Biol 2014,. May 5. [Epub ahead of print].

17. Neve RM, Chin K, Fridlyand J, Yeh J, Baehner FL, Fevr T, Clark L, Bayani N, Coppe JP, Tong F, Speed T, Spellman PT, DeVries S, Lapuk A, Wang NJ, Kuo WL, Stilwell JL, Pinkel D, Albertson DG, Waldman FM, McCormick F, Dickson RB, Johnson MD, Lippman M, Ethier S, Gazdar A, Gray JW: A collection of breast cancer cell lines for the study of functionally distinct cancer subtypes. Cancer Cell 2006, 10:515-527.
18. Eddy SF, Kane SE, Sonenshein GE: Trastuzumab-resistant HER2-driven breast cancer cells are sensitive to epigallocatechin-3 gallate. Cancer Res 2007, 67:9018-9023.

19. Hagen KR, Zeng X, Lee MY, Tucker Kahn S, Harrison Pitner MK, Zaky SS, Liu Y, O'Regan RM, Deng X, Saavedra HI: Silencing CDK4 radiosensitizes breast cancer cells by promoting apoptosi. Cell Div 2013, 8:8.

20. Gyorffy B, Lanczky A, Eklund AC, Denkert C, Budczies J, Li Q, Szallasi Z: An online survival analysis tool to rapidly assess the effect of 22,277 genes on breast cancer prognosis using microarray data of 1,809 patients. Breast Cancer Res Treat 2010, 123:725-731.

21. Zorn AM: Cell-cell signalling: frog frizbees. Curr Biol 1997, 7:R501-504.

22. Ugolini F, Adelaide J, Charafe-Jauffret E, Nguyen C, Jacquemier J, Jordan B, Birnbaum D, Pebusque MJ: Differential expression assay of chromosome arm 8p genes identifies Frizzled-related (FRP1/FRZB) and Fibroblast Growth Factor Receptor 1 (FGFR1) as candidate breast cancer genes. Oncogene 1999, 18:1903-1910.

23. Veeck J, Niederacher D, An H, Klopocki E, Wiesmann F, Betz B, Galm O, Camara O, Durst M, Kristiansen G, Huszka C, Knüchel R, Dahl E: Aberrant methylation of the Wnt antagonist SFRP1 in breast cancer is associated with unfavourable prognosis. Oncogene 2006, 25:3479-3488.

24. Klopocki E, Kristiansen G, Wild PJ, Klaman I, Castanos-Velez E, Singer G, Stohr R, Simon R, Sauter G, Leibiger H, Essers L, Weber B, Hermann K, Rosenthal A, Hartmann A, Dahl E: Loss of SFRP1 is associated with breast cancer progression and poor prognosis in early stage tumors. Int J Oncol 2004, 25:641-649.

25. Wong SC, Lo SF, Lee KC, Yam JW, Chan JK, Wendy Hsiao WL: Expression of frizzled-related protein and Wnt-signalling molecules in invasive human breast tumours. J Pathol 2002, 196:145-153.

26. Ugolini F, Charafe-Jauffret E, Bardou VJ, Geneix J, Adelaide J, Labat-Moleur F, Penault-Llorca F, Longy M, Jacquemier J, Birnbaum D, Pebusque MJ: WNT pathway and mammary carcinogenesis: loss of expression of candidate tumor suppressor gene SFRP1 in most invasive carcinomas except of the medullary type. Oncogene 2001, 20:5810-5817.

27. Gauger KI, Shimono A, Crisi GM, Schneider SS: Loss of SFRP1 promotes ductal branching in the murine mammary gland. BMC Dev Biol 2012, 12:25.

28. Matsuda $Y$, Ichida $T$ : Impact of hepatitis $B$ virus $X$ protein on the DNA damage response during hepatocarcinogenesis. Med Mol Morphol 2009, 42:138-142.

29. Cooper SJ, von Roemeling CA, Kang KH, Marlow LA, Grebe SK, Menefee ME, Tun HW, Colon-Otero G, Perez EA, Copland JA: Reexpression of tumor suppressor, sFRP1, leads to antitumor synergy of combined HDAC and methyltransferase inhibitors in chemoresistant cancers. Mol Cancer Ther 2012, 11:2105-2115.

30. Momand J, Zambetti GP, Olson DC, George D, Levine AJ: The mdm-2 oncogene product forms a complex with the p53 protein and inhibits p53-mediated transactivation. Cell 1992, 69:1237-1245.

31. Wade M, Li YC, Wahl GM: MDM2, MDMX and p53 in oncogenesis and cancer therapy. Nat Rev Cancer 2013, 13:83-96.

32. Fahraeus R, Olivares-lllana V: MDM2's social network. Oncogene 2014, 33:4365-4376

33. Martin K, Trouche D, Hagemeier $C$, Kouzarides T: Regulation of transcription by E2F1/DP1. J Cell Sci Supp/ 1995, 19:91-94.

34. Shibagaki I, Tanaka H, Shimada Y, Wagata T, Ikenaga M, Imamura M, Ishizaki K: p53 mutation, murine double minute 2 amplification, and human papillomavirus infection are frequently involved but not associated with each other in esophageal squamous cell carcinoma. Clin Cancer Res 1995, 1:769-773.

35. Ito M, Barys L, O'Reilly T, Young S, Gorbatcheva B, Monahan J, Zumstein-Mecker S, Choong PF, Dickinson I, Crowe P, Hemmings C, Desai J, Thomas DM, Lisztwan J: Comprehensive mapping of p53 pathway alterations reveals an apparent role for both SNP309 and MDM2 amplification in sarcomagenesis. Clin Cancer Res 2011, 17:416-426.

36. Forslund A, Zeng Z, Qin LX, Rosenberg S, Ndubuisi M, Pincas H, Gerald W, Notterman DA, Barany F, Paty PB: MDM2 gene amplification is correlated to tumor progression but not to the presence of SNP309 or TP53 mutational status in primary colorectal cancers. Mol Cancer Res 2008, 6:205-211.

37. Araki S, Eitel JA, Batuello CN, Bijangi-Vishehsaraei K, Xie XJ, Danielpour $D_{\text {, }}$ Pollok KE, Boothman DA, Mayo LD: TGF-beta1-induced expression of human $\mathrm{Mdm} 2$ correlates with late-stage metastatic breast cancer. J Clin Invest 2010, 120:290-302. 
38. Chen X, Qiu J, Yang D, Lu J, Yan C, Zha X, Yin Y: MDM2 promotes invasion and metastasis in invasive ductal breast carcinoma by inducing matrix metalloproteinase-9. PLoS One 2013, 8:e78794.

39. Carroll PE, Okuda M, Horn HF, Biddinger P, Stambrook PJ, Gleich LL, Li YQ, Tarapore $P$, Fukasawa K: Centrosome hyperamplification in human cancer: chromosome instability induced by p53 mutation and/or Mdm2 overexpression. Oncogene 1999, 18:1935-1944.

40. Ganguli G, Wasylyk B: p53-independent functions of MDM2. Mol Cancer Res 2003, 1:1027-1035

41. Alt JR, Greiner TC, Cleveland JL, Eischen CM: Mdm2 haplo-insufficiency profoundly inhibits Myc-induced lymphomagenesis. EMBO J 2003, 22:1442-1450

42. Cordon-Cardo C, Latres E, Drobnjak M, Oliva MR, Pollack D, Woodruff JM, Marechal V, Chen J, Brennan MF, Levine AJ: Molecular abnormalities of mdm2 and p53 genes in adult soft tissue sarcomas. Cancer Res 1994, 54:794-799.

43. Lu ML, Wikman F, Orntoft TF, Charytonowicz E, Rabbani F, Zhang Z, Dalbagni G, Pohar KS, Yu G, Cordon-Cardo C: Impact of alterations affecting the p53 pathway in bladder cancer on clinical outcome, assessed by conventional and array-based methods. Clin Cancer Res 2002, 8:171-179.

44. Meraldi P, Honda R, Nigg EA: Aurora-A overexpression reveals tetraploidization as a major route to centrosome amplification in p53-/- cells. EMBO J 2002, 21:483-492.

45. Zhou H, Kuang J, Zhong L, Kuo WL, Gray JW, Sahin A, Brinkley BR, Sen S: Tumour amplified kinase STK15/BTAK induces centrosome amplification, aneuploidy and transformation. [see comments.]. Nat Genet 1998, 20:189-193.

46. Zeng X, Shaikh FY, Harrison MK, Adon AM, Trimboli AJ, Carroll KA, Sharma $\mathrm{N}$, Timmers C, Chodosh LA, Leone G, Saavedra HI: The Ras oncogene signals centrosome amplification in mammary epithelial cells through cyclin D1/Cdk4 and Nek2. Oncogene 2010, 29:5103-5112.

47. Kitajima TS, Sakuno T, Ishiguro K, lemura S, Natsume T, Kawashima SA, Watanabe Y: Shugoshin collaborates with protein phosphatase $2 \mathrm{~A}$ to protect cohesin. Nature 2006, 441:46-52.

48. Liu H, Rankin S, Yu H: Phosphorylation-enabled binding of SGO1-PP2A to cohesin protects sororin and centromeric cohesion during mitosis. Nat Cell Biol 2013, 15:40-49.

49. Kitajima TS, Kawashima SA, Watanabe Y: The conserved kinetochore protein shugoshin protects centromeric cohesion during meiosis. Nature 2004, 427:510-517.

50. Lee J, Kitajima TS, Tanno Y, Yoshida K, Morita T, Miyano T, Miyake M, Watanabe $Y$ : Unified mode of centromeric protection by shugoshin in mammalian oocytes and somatic cells. Nat Cell Biol 2008, 10:42-52.

51. Tang Z, Sun Y, Harley SE, Zou H, Yu H: Human Bub1 protects centromeric sister-chromatid cohesion through Shugoshin during mitosis. Proc Natl Acad Sci U S A 2004, 101:18012-18017.

52. Takata H, Matsunaga S, Morimoto A, Ma N, Kurihara D, Ono-Maniwa R, Nakagawa M, Azuma T, Uchiyama S, Fukui K: PHB2 protects sister-chromatid cohesion in mitosis. Curr Biol 2007, 17:1356-1361.

53. Fu G, Ding X, Yuan K, Aikhionbare F, Yao J, Cai X, Jiang K, Yao X: Phosphorylation of human Sgo1 by NEK2A is essential for chromosome congression in mitosis. Cell Res 2007, 17:608-618.

54. Scanlan MJ, Gout I, Gordon CM, Williamson B, Stockert E, Gure AO, Jager D, Chen YT, Mackay A, O'Hare MJ, Old LJ: Humoral immunity to human breast cancer: antigen definition and quantitative analysis of mRNA expression. Cancer Immun 2001, 1:4.

55. Wang Y, Liu L, Liu X, Zhang H, Liu J, Feng B, Shang Y, Zhou L, Wu K, Nie Y, Zhang $H$, Fan D: Shugoshin1 enhances multidrug resistance of gastric cancer cells by regulating MRP1, Bcl-2, and Bax genes. Tumour Biol 2013, 34:2205-2214

56. Kahyo T, Iwaizumi M, Shinmura K, Matsuura S, Nakamura T, Watanabe Y, Yamada $\mathrm{H}$, Sugimura $\mathrm{H}$ : A novel tumor-derived SGOL1 variant causes abnormal mitosis and unstable chromatid cohesion. Oncogene 2011, 30:4453-4463.

57. Yang J, Ikezoe T, Nishioka C, Yokoyama A: A novel treatment strategy targeting shugoshin 1 in hematological malignancies. Leuk Res 2013, 37:76-82.

58. Iwaizumi M, Shinmura K, Mori H, Yamada H, Suzuki M, Kitayama Y, Igarashi H, Nakamura T, Suzuki H, Watanabe Y, Hishida A, Ikuma M, Sugimura H: Human Sgo1 downregulation leads to chromosomal instability in colorectal cancer. Gut 2009, 58:249-260.
59. Leber B, Maier B, Fuchs F, Chi J, Riffel P, Anderhub S, Wagner L, Ho AD Salisbury $J$, Boutros M, Kramer A: Proteins required for centrosome clustering in cancer cells. Sci Transl Med 2010, 2:33ra38.

60. Lan W, Cleveland DW: A chemical tool box defines mitotic and interphase roles for Mps1 kinase. J Cell Biol 2010, 190:21-24.

61. Pike AN, Fisk HA: Centriole assembly and the role of Mps1: defensible or dispensable? Cell Div 2011, 6:9.

62. Kasbek $\mathrm{C}$, Yang $\mathrm{CH}$, Fisk HA: Antizyme restrains centrosome amplification by regulating the accumulation of Mps1 at centrosomes. Mol Biol Cell 2010, 21:3878-3889.

63. Kasbek C, Yang CH, Fisk HA: Mps1 as a link between centrosomes and genomic instability. Environ Mol Mutagen 2009, 50:654-665.

64. Daniel J, Coulter J, Woo JH, Wilsbach K, Gabrielson E: High levels of the Mps 1 checkpoint protein are protective of aneuploidy in breast cancer cells. Proc Natl Acad Sci U S A 2011, 108:5384-5389.

65. Maire V, Baldeyron C, Richardson M, Tesson B, Vincent-Salomon A, Gravier E, Marty-Prouvost B, De Koning L, Rigaill G, Dumont A, Gentien D, Barillot E, Roman-Roman S, Depil S, Cruzalegui F, Pierré A, Tucker GC, Dubois T: TTK/ hMPS1 is an attractive therapeutic target for triple-negative breast cancer. PLoS One 2013, 8:e63712.

66. Yuan B, Xu Y, Woo JH, Wang Y, Bae YK, Yoon DS, Wersto RP, Tully E, Wilsbach K, Gabrielson E: Increased expression of mitotic checkpoint genes in breast cancer cells with chromosomal instability. Clin Cancer Res 2006, 12:405-410.

doi:10.1186/1747-1028-9-3

Cite this article as: Lee et al:: Differential expression of centrosome regulators in Her2+ breast cancer cells versus non-tumorigenic MCF10A cells. Cell Division 2014 9:3.

\section{Submit your next manuscript to BioMed Central and take full advantage of:}

- Convenient online submission

- Thorough peer review

- No space constraints or color figure charges

- Immediate publication on acceptance

- Inclusion in PubMed, CAS, Scopus and Google Scholar

- Research which is freely available for redistribution

Submit your manuscript at www.biomedcentral.com/submit
C Biomed Central 